\title{
Exploring resource management for sustainable food businesses: Three Vermont case studies
}

\author{
David S. Conner* \\ University of Vermont
}

Submitted July 26, 2019 / Revised October 2 and October 30, 2019 / Accepted October 30, 2019 /

Published online March 16, 2020

Citation: Conner, D. S. (2020). Exploring resource management for sustainable food businesses:

Three Vermont case studies. Journal of Agriculture, Food Systems, and Community Development, 9(3), 99-107.

https://doi.org/10.5304/jafscd.2020.093.002

Copyright (C) 2020 by the Author. Published by the Lyson Center for Civic Agriculture and Food Systems. Open access under CC-BY license.

\begin{abstract}
This paper is an exploratory comparative case study of three Vermont food businesses. It examines the use of transaction cost and knowledge management theories to understand how food businesses with sustainability missions make key management decisions about resource allocation (the "make or buy" decision). Results suggest that these businesses' decisions are driven in part by their personal values and interests and their desire to support other local businesses and contribute to their communities. Their decisions also largely conform to what the aforementioned theories would predict: specifically, they make inputs and services that are within their core competencies, they form partnerships to procure key inputs and support other

\footnotetext{
* David S. Conner, Associate Professor, Department of Community Development and Applied Economics, University of Vermont; 205H Morrill Hall; 146 University Place; Burlington, VT 05405 USA; +1-802-656-1965; david.conner@uvm.edu
}

local businesses, and they buy inputs readily available in existing markets in order to free up their time and increase efficiency. Furthermore, they allocate their own time to activities they enjoy or those with high strategic value for the business. The discussion focuses on how these findings may guide future research and how these theoretical frameworks may be used to better understand entrepreneur behavior, foster mutually beneficial partnerships, and advance sustainability missions in food business.

\section{Keywords}

Transaction Costs, Knowledge Management, Make or Buy Decision, Sustainable Food System, Food Business

\section{Funding Disclosure}

This research was supported by U.S. Department of Agriculture Hatch formula funds administered by the Vermont Agricultural Experiment Station. 


\section{Introduction}

The food system plays a large and vital role in the well-being of individuals and communities in the United States as a whole, as well as in individual states such as Vermont (Conner, Sims, Berkfield, \& Harrington, 2017; Conner et al., 2013; Vermont Sustainable Jobs Fund, 2013). In addition, the food and agriculture sector is a significant part of the Vermont economy (Conner et al., 2013); indeed, Vermont has a statewide strategic plan that places food and agriculture at the forefront of economic development efforts (Vermont Sustainable Jobs Fund, 2013). As such, the food system plays a significant role in community development and quality of life, with profound impacts on social and economic well-being, land use, and public health (Conner \& Levine, 2006; Conner et al., 2017). Forprofit businesses are critical actors in the Vermont food system, notably those firms with social responsibility and sustainability missions, as they help achieve planned community development outcomes (Conner, DeWitt, Inwood, \& Archer, 2015).

Heretofore, the vast majority of economic research has utilized neoclassical economic theory and its underlying assumptions that the sole objective of a firm is profit maximization (Alexander, 2007). Critics assert that the imposition of this paradigm provides limited insights into understanding the behavior of firms, particularly where social responsibility and sustainability missions are salient (Alexander, 2007; Hobbs, 1996). Two alternative theories that have provided insights into sustainability are transaction cost and knowledge management (Carter \& Easton, 2011; Peterson, 2008). Carter and Easton (2011) note that transaction cost theory has been vastly underutilized in analyses of sustainability efforts and suggest this theory as an important direction of future research. Knowledge management has been cited as key to sustainability and addressing complex problems in food supply chains (Peterson, 2008).

In this paper, I present exploratory research on three food businesses in Vermont in order to test the further development of methods that utilize transaction cost and knowledge management theories as ways to understand how these firms are able to balance profitability, lifestyle, and sustainability goals. Specifically, I apply theories of transaction costs and knowledge management to better understand strategic decisions involving management and resource allocation. First, I review previous research. Then I describe the methods utilized for this research and present and discuss the results of three case studies, concluding with implications for future research and outreach.

\section{Literature Review}

Many businesses balance profitability with a social mission that promotes community well-being and sustainability, measuring performance along the triple bottom line of economic, social, and environmental measures-which has been referred to as people, planet, and profit (Carroll, 1979; Conner et al., 2015; Inyang, 2013; Jenkins, 2006; Kakava, Mbizi, \& Manyeruke, 2013). Previous research in Vermont has found that food-based businesses are committed to a broad array of socially responsible goals and actions, including concern for the environment and use of ecologically friendly practices; contributing to local economic development, including supporting local businesses; providing support for the welfare of supply chain partners; and balancing financial interests (both self and investors) with personal quality of life and external social goals (Conner et al., 2015). These indicators of social responsibility and sustainability mirror those of previous studies (Carroll, 1979; Fitzgerald, Haynes, Schrank, \& Danes, 2010; Inyang, 2013; Kakava et al., 2013).

\section{Make or Buy}

In order to succeed in the marketplace and meet sustainability goals, entrepreneurs must use resources (including their own time) wisely. The seminal work of Coase (1937), discussing how a firm procures inputs (the "make or buy" decision), theorized that a firm will buy commoditized inputs, which are readily and routinely available in established markets, but may need to make inputs which are highly specialized and not readily available. Transaction costs (finding suppliers, negotiating prices, and monitoring quality and enforcement) increase as the input attributes become more specialized and unusual. A firm will buy an input as long as the transaction costs - the effort it takes to find an item negotiate price and monitor quality- 
is manageable. Williamson (1990) further discussed how these make or buy decisions outline the efficient boundary of the firm. More recently, scholars have described three models for input procurement: spot markets, vertical integration/hierarchy, and strategic partnership (Conner, Izumi, Liquori, \& Hamm, 2012; Hobbs, 1996). Spot markets are used for low transaction cost inputs which are uniform and widely available: the firm simply chooses the lowest cost option. The vertical integration/hierarchy approach is used when inputs are unique or highly specialized: the firm may need to produce it if suppliers are not easily found, and/or when the resources needed to produce it are highly specialized. Strategic partnership occupies the middle ground; the firm can procure differentiated inputs but not spend the resources to own and control its production, hence focusing efforts on activities within its efficient boundary.

Partnerships have proven to be effective in helping institutional foodservice operations to meet local food procurement and educational goals (Conner et al., 2011; Conner et al., 2012). Farmers partner with food hubs, which in a sense "buys" marketing and distribution services from the food hubs rather than "making" them themselves, thus gaining market access, year-round revenue, and assistance with branding (Conner et al., 2017).

\section{Knowledge Management}

Methods of managing and sharing knowledge also affect decisions around resource use. One useful model is the management of explicit, tacit, and cocreated knowledge. This model has been applied to sustainability initiatives by Peterson (2008) and to entrepreneurial education by my colleagues and me (Conner, Becot, Kolodinsky, Resnicow, \& Woodruff, 2014). In this theoretical approach, explicit knowledge can be written or spoken, tacit knowledge is gained by experience, and co-created knowledge is gained through innovation and collaboration. Peterson (2008) argues that while explicit knowledge has the lowest potential for innovation and strategic value, co-created knowledge, although uncertain, dynamic, and unpredictable, nevertheless has the highest potential value. My colleagues and I (Conner et al., 2014) argue that all three are needed in order for entrepre- neurs to discover and act upon opportunities.

The transaction cost (make or buy) and knowledge management models also highlight the use of human resource services (e.g., bookkeeping, production, management, marketing) and their effect on an entrepreneur's time. Hypothetically, as a firm evolves and grows, the entrepreneur's time should be allocated toward its highest strategic value. Labor tasks that require only explicit knowledge will be performed essentially the same way by any person, and in any business application should be allocated to hired labor: the entrepreneur "buys" this labor input from another person (i.e., an employee or contractor). In contrast, for tasks that require specialized knowledge, either from experience within the firm (tacit) or from collaboration and innovation with external entities (cocreation), the labor input is highly specialized and context-specific. In these cases, it would be difficult to find employees able to perform these tasks, and the entrepreneur would choose to "make" these inputs by allocating their own time to them. Hence, the entrepreneur's time evolves from spending less time working "in" the business (performing explicit knowledge tasks with low strategic value) to spending more time working "on" the business (performing co-created knowledge with high strategic value).

In this paper, I examine the utility of the transaction cost and knowledge management frameworks in the context of three Vermont food businesses with sustainability goals. This research fills a gap in the extant literature by combing these frameworks to understand resource allocation and sustainability in food businesses by testing the applicability of these methods in a small sample. Specifically, this paper addresses these research questions: How do entrepreneurs choose and operationalize sustainability goals, particularly in balance with profit and quality of life? To what extent do key decisions around resource allocation conform to what transaction cost and knowledge management theories would predict?

\section{Methods}

I used key informant interviews with the founding entrepreneurs of three Vermont-based food businesses. Each is in my network of professional con- 
tacts. Two are owned by individuals; the third is owned by a married couple. ${ }^{1}$ They were chosen to participate as cases in this study primarily due to their strong sustainability missions and successes in forming partnerships with other local businesses. Table 1 provides information on each business.

\section{Data Collection and Analysis}

I developed a semistructured interview guide that included questions on the following topics:

- the business's origins, evolution, and mission

- core competencies, make or buy decisions, and boundaries of the firm

- partnerships, their origins and evolution, services and functions provided

- knowledge management

- how partnerships affect management, performance, scope, scale, and achievement of sustainability goals

The three businesses were contacted via email and asked to participate. The interviews took place in the entrepreneurs' homes and lasted 60-90 minutes. I used standard qualitative data analysis methods (Miles \& Huberman, 1994; Patton, 2002) to highlight important themes from the interviews and answer the research questions, using HyperResearch software (version 4.0.0) (Researchware, Inc., 2015). This software allows the user to highlight text, tag it with a code, and identify all text that is tagged with a given code for easy retrieval. A total of 15 codes were identified. The interview guide and list of codes are available on request. The Results section will present crucial themes emerging from the analysis, along with representative quotations.

\section{Results}

\section{Motivations and Values}

These businesses reflect the values of the entrepreneurs in their origins, mission, and evolution. Quality of life is important to all three. SS began as a small farm and evolved into a food service provider as a market for their produce: "it was both intention and trial and error." MW began their business as a livelihood strategy "to live here and pay the bills," while VT wanted to have a business that would allow for more family time and less travel than the consulting work they had been doing. They decided to "open a business, like Vermonters do."

The principles of sustainability, and of consideration of economic, social, and environmental factors, continue to guide their operations. All three actively seek out ingredients from local farms and vendors, particularly those using sustainable production methods. SS continues to support farms that share space with their original farm at a local farm incubator organization, as well as to expand to purchasing from a distributor specializing in locally grown foods. MW sources only organic and/or non-GMO ingredients, with the goal of "creating balance for a resilient ecosystem." MW has largely replaced purchases of Fair Trade palm oil with local sunflower oil. Their overall goal in procurement is to "rebuild local infrastructure for community food systems," in this case by supporting "lots of diverse, decentralized small-scale oil processing suppliers." VT merges their "interests in soil science and local food" by "develop[ing] a value-added product supporting local farmers." They are dedicated to "supporting Lake Champlain basin farmers." MW emphasizes the desire to "help people and products push for a better tomorrow"

Table 1. Description of Sample Cases

\begin{tabular}{lcccc}
\hline Firm Name & Primary Product & Year of Origin & $\begin{array}{c}\text { 2018 Gross Sales } \\
\text { (US\$) }\end{array}$ & $\begin{array}{c}\text { Number of Employees (full-time equiva } \\
\text { lent, including owner-operators) }\end{array}$ \\
\hline SS & Catering & 2003 & $\$ 1.5$ million & 12, plus seasonal \\
\hline MW & Baked goods & 2015 & $\$ 120,000$ & 1.5 \\
\hline VT & Tortillas & 2016 & $\$ 510,000$ & 6.5 \\
\hline
\end{tabular}

1 To address the diversity of gender identities in the sample, the pronoun "they" is used throughout. 
and "get better at self-reliance with community support."

\section{The Make Decision}

The decisions about what to "make" rather than "buy"- the use of their businesses' capacity and of their own time-is guided by a combination of their values, interests, and expertise, as well as by market forces. SS continues to grow certain items on the farm, particularly fresh herbs not available through distributors, produce they can quickly and efficiently process and store (e.g., tomatoes and winter squash), and items they can re-use, such as drying flowers and ornamental gourds for table centerpieces. MW enjoys making packaging from old flour containers to "give them a second life." MW also preserves produce items (e.g., making glazes from berries and apples), buying them when they are abundant, fresh, and relatively inexpensive and using their culinary skills and resources to create products that "change flavors every two weeks with changes in ecology and the season." The use of local products and changing flavors for MW's products creates "value though scarcity and shorts" because they intentionally limit the quantity of each item in order to make it more rare and valuable. VT focuses solely on two products within their core competency: tortillas and masa (the raw material of tortillas).

The entrepreneurs' use of their time is similarly driven by their preferences and abilities. As SS "enjoys financial analysis "and "being the Chief Financial Officer," SS's role is to oversee the business, focusing on "big picture" issues of management and strategy. SS spends little time on food preparation or sales. Rather, SS focuses on the question, "What do I have to do to get the phone to ring?" SS focuses on tasks of high strategic value, involving tacit knowledge of business management and co-creating knowledge with partners (such as improving relationships with suppliers and venues), rather than explicit knowledge tasks of food preparation. SS is the oldest business, and they have the clearest evidence of allocating time to the highest strategic value. MW is motivated by one principle: "I want to be in the kitchen." MW's extensive use of local inputs which vary in their composition and therefore in the final product's texture- "Saturday fluffy, Sunday dense" —also requires them to do the baking themselves. "The problem with small local farms is consistency," they explain. "It would not be feasible to hire an employee to bake because the recipe changes every time." Rather, MW utilizes tacit knowledge to mill the grains and bake the product, as such explicit knowledge, like a recipe, would be inadequate. VT has a clear division of labor based on skills and interests; one partner focuses on finance and marketing, while the other focuses on production.

\section{The Buy Decision}

Two themes emerged from study of the items or services that the businesses "buy." First, they are fairly routine (one size fits all) inputs; second, they save the business "making" time. SS buys many food items from a distributor who is "reliable, ensures food safety" and "sells cuts of meat," saving SS the time required to source from multiple farms and break down whole animals. MW buys "base neutral" transitional flour from Quebec to balance out and make up for shortages of flour from smaller, more local sources. MW hires employees to perform explicit knowledge tasks, such as delivering product and helping with routine food-processing chores. VT utilizes distributors who have reach into distant regions. They also hire consultants in order to interface with a large distributor, perform food demonstrations in an out-of-state city, and run their social media campaigns.

\section{Partnership}

The businesses have partnerships that have advanced their goals. In addition to their supplying farms and distributors, SS's most important partners are the venues for which they cater. SS states that "every venue is a client" and "venue relationships are everything." Perhaps the most important venue is a local children's museum. SS began by running its cafeteria, as a loss leader strategy in order to drive catering. After several iterations, including stepping away from the relationship for a few months, SS now only caters events at the museum, and is no longer responsible for vending at the cafeteria. SS posits two important questions to consider: "How can we be a 
better partner?" and "How can we drive business to each other?" Keys to a successful partnership are "to make each other look good" and "to know the rules and expectations of each venue" (e.g., key and door policies, septic and electrical resources) so that the venue manager "does not have to manage the caterer." In many cases, including the museum, the venue is a nonprofit organization and events and catering provide a substantial source of unrestricted funds.

MW's major partners are the coffee shops and convenience stores that sell their pastries. MW began selling at a high-end coffee shop chain that invited them to do a "pop-up" pastry sale in one of their locations. Building on this success, the shop helped MW develop a business plan and expand operations. One key to their success is their ability to "promote each other." Although MW has since expanded to 12 locations, the original partner "gets all the new flavors" and serves as the test audience. Knowing the customers of the various partners is critical. Those who "sell lattes get the exotic flavors" but MW "sticks to maple for those who sell [US]\$1 gas station coffee."

VT's most important partner is the farm from which they buy organic dent corn, the raw ingredient for the masa that is the principal ingredient for their tortillas. This partner has made investments in storage and cleaning equipment in order to deliver a clean product, saving VT the time and effort of picking up and cleaning the grain. In return, VT pays an above-market price for the product.

One overarching theme in the partnerships are the values of patience, trust, and ongoing communication. SS was able to reconnect with the museum based on trust earned from previous partnerships. "Don't burn bridges" is a central theme in their partnership strategy. VT advises businesses to "listen more than speak" and to understand that "often 'no' only means 'not now." VT also advises communicating with other businesses in order to improve own's own, including sharing profit and loss statements with similarly sized businesses and asking for advice on managing growth from slightly larger businesses. In addition, VT cautions against demeaning the products of others in an effort to promote one's own.
Markets

The theme of market channels emerged from the data themselves, rather than having been preformed based on the questions asked. An important theme in the choice of market channels is movement from direct sales ("vending") to wholesale. Each business found that "making" their own marketing services through selling direct to consumers (vending) was both time-consuming and risky. By selling wholesale- thus "buying" marketing services from others-each business is able to have more predictable sales and spend less time selling. Each now has limited direct sales, in two cases using it mainly for marketing and testing new products.

SS began by renting "the old chicken wings place" on a busy road and selling "high-end takehome meals" to commuters. Over the next few years they added catering, mostly delivering catered business lunches. "Retail growth was slow, catering growth was rapid." SS also moved from vending to solely catering at the museum. Now all sales are prepaid except for cash-bar sales at events. This transition away from vending lends SS "cost control, less staff and less stress." SS adds, "Vending is fickle; it involves planning and guesswork around the weather. In the end, dropping vending lowered employee turnover, food costs, labor costs, and increased our focus."

MW has expanded to 12 wholesale accounts, although they still do some vending at a small neighborhood farmers market. "Wholesale accounts have standing orders. They get standard products, doughnuts and cakes. It pays the rent." On the other hand, the farmers market is a "test for what my community needs" and allows for experimentation on a smaller scale.

VT began selling at farmers markets and doing "pop-up dinners" at the same local farmers market where MW sells, but found that these markets involved "lots of time and ingredients, but no profit. We did not want to invest in brick and mortar," so they transitioned to wholesale sales. Currently, they only provide samples at trade shows and that only as a way to "build morale and brand."

\section{Discussion and Conclusions}

This paper utilizes transaction cost and knowledge 
management theories to analyze decisions around resource allocation for three Vermont food businesses. These theories are promising alternatives to the more prominent neoclassical theory and assumptions of profit maximization, particularly for understanding firms with sustainability missions (Alexander, 2007; Carter \& Easton, 2011; Hobbs, 1996; Peterson, 2008). The contribution of this study to the literature is the use of these frameworks in analysis of for-profit firms with sustainability goals as proof that the concepts can be fruitful for future study. As previous research results have indicated, these kinds of entrepreneurs have strong sustainability missions, notably around supporting other local businesses and being stewards of the environment while maintaining their personal quality of life (Carroll, 1979; Conner et al., 2015; Fitzgerald, Haynes, Schrank, \& Danes, 2010; Inyang, 2013; Kakava et al., 2013). Each has been able to incorporate their values and passions into their business operations. Notably, the goal of profit maximization, predicted by neoclassical theory, was not mentioned by any respondent.

Their make or buy decisions and the efficient boundaries of the firms tend to align well with transaction cost theory (Coase, 1937; Conner et al., 2012; Hobbs, 1996; Williamson, 1990). In terms of vertical integration/hierarchy, each makes products with varying proportions of local ingredients, using their expertise to transform and add value. For example, SS uses its capacity to process and store produce efficiently and to grow herbs not commonly available. Similarly, MW preserves produce to make unique glazes that are not generally available to buy. In contrast, in terms of the concept of spot markets, they buy items which are available elsewhere: SS extensively uses a distributor with a wide array of local products and MW buys flour. Each business has key partners who drive business to each other, as with SS and MW, or who are invested in equipment in order to supply a unique input (e.g., stored, cleaned, and delivered dent corn). The use of entrepreneurs' time aligns with tasks they enjoy (e.g., MW personally enjoys baking), as well as tasks, such as SS's management and partnership formation, that require tacit or co-created knowledge and therefore have higher strategic value. This paper also applies the make or buy de- cision model to interpret entrepreneurs' time allocation and market channel decisions, which is a novel contribution to the literature.

The strength of this paper is the novel use of these theories, as applied to three very different cases, as evidence that they have utility for future inquiry. Notably, it proposes theoretical frameworks beyond the dominant neoclassical paradigm that will better explain firm behavior. The chief weakness of this study is the small, unrepresentative, and narrow sample and lack of generalizability to other samples.

\section{Implications}

This paper explores the operationalization of sustainability goals for research purposes and the usefulness of these two theories as applied to food businesses. It is highly exploratory research, intended as a pilot study for future research to further understand and guide the management of sustainable food businesses. Future research can take a number of directions. First, more research on these three businesses (e.g., analysis of financial documents, and customer and buyer interviews) could provide greater depth of understanding of these firms' decisions and their impacts. Second, key informant interviews of food businesses with no sustainability missions and non-food businesses with sustainability missions would provide further comparisons. Third, surveys can provide data from a large number of firms (e.g., food and non-food, with and without sustainability missions) to tabulate and correlate prevalences of attributes, goals, and behaviors. A greater understanding of when decisions align with sustainability principles and, more importantly, when and why they do not, would add nuances to understanding entrepreneur behavior and guide better education and outreach efforts. Important future topics would include the trade-offs and changes in firm boundary when sustainability goals are pursued.

Make or buy decisions can be incorporated into agri-business and food entrepreneurship courses, as well as farm viability programming. Decision cases can be developed to further refine our understanding of the make or buy model and its utility. In addition, education and outreach can highlight the potential benefits of forming partner- 
ships and their role in enhancing profitability and entrepreneurs' quality of life, and advancing sustainability missions. It is my hope that the information in this paper will inform future research and ultimately improve decision making and facilitate more effective adoption of sustainability principles by businesses of all types.

\section{References}

Alexander, J. (2007). Environmental sustainability versus profit maximization: Overcoming systemic constraints on implementing normatively preferable alternatives. Journal of Business Ethics, 76(2), 155-162. https://doi.org/10.1007/s10551-006-9264-5

Carroll, A. B. (1979). Three-dimensional conceptual model of corporate performance. Academy of Management Review, 4(4), 497-505. https://doi.org/10.2307/257850

Carter, C. R., \& Easton, P. L. (2011). Sustainable supply chain management: Evolution and future directions. International Journal of Physical Distribution and Logistics Management, 41(1), 46-62. https://doi.org/10.1108/09600031111101420

Coase, R. H. (1937). The nature of the firm. Economica, 4(16), 386-405. https://doi.org/10.1111/j.1468-0335.1937.tb00002.x

Conner, D., Becot, F., Kahler, E., Sawyer, S., Hoffer, D., \& Berlin, L. (2013). Measuring current consumption of locally grown foods in Vermont: Methods for baselines and targets. Journal of Agriculture, Food Systems, and Community Development, 3(3), 83-94. https://doi.org/10.5304/jafscd.2013.033.004

Conner, D., Becot, F., Kolodinsky, J., Resnicow, S., \& Woodruff, K. F. (2014). Fostering the next generation of agrifood entrepreneurs in Vermont: Implications for university-based education. NACTA Journal, 58(3), 221-229. https://www.jstor.org/stable/nactajournal.58.3.221

Conner, D., DeWitt, R.-L., Inwood, S., \& Archer, M. (2015). Social responsibility and community development in Vermont's food business sector. Journal of Food Research, 4(6), 93-103. https://doi.org/10.5539/ifr.v4n6p93

Conner, D. S., Izumi, B. T., Liquori, T., \& Hamm, M. W. (2012). Sustainable school food procurement in large K-12 districts: Prospects for value chain partnerships. Agricultural and Resource Economics Review, 41(1), 100-113. https://doi.org/10.1017/S1068280500004226

Conner, D. S., \& Levine, R. (2006). Circles of association: The connections of community-based food systems. Journal of Hunger \& Environmental Nutrition, 1(3) 5-25. https://doi.org/10.1300/J477v01n03_02

Conner, D. S., Nowak, A., Berkenkamp, J., Feenstra, G., Kim, J. v. S., Liquori, T., \& Hamm, M. W. (2011). Value chains for sustainable procurement in large school districts: Fostering partnerships. Journal of Agriculture, Food Systems, and Community Development, 1(4), 1-14. https://doi.org/10.5304/jafscd.2011.014.005

Conner, D. S., Sims, K., Berkfield, R., \& Harrington, H. (2017). Do farmers and other suppliers benefit from sales to food hubs? Evidence from Vermont. Journal of Hunger \& Environmental Nutrition, 13(4), 507-516. https://doi.org/10.1080/19320248.2017.1378602

Fitzgerald, M. A., Haynes, G. W., Schrank, H. L., \& Danes, S. M. (2010). Socially responsible processes of small family business owners : Exploratory evidence from the National Family Business Survey. Journal of Small Business Management, 48(4), 524-551. https://doi.org/10.1111/j.1540-627x.2010.00307.x

Hobbs, J. E. (1996). A transaction cost approach to supply chain management. Supply Chain Management: An International Journal, 1(2), 15-27. https://doi.org/10.1108/13598549610155260

Inyang, B. J. (2013). Defining the role engagement of small and medium-sized enterprises (SMEs) in corporate social responsibility (CSR). International Business Research, 6(5), 123-133. https://doi.org/10.5539/ibr.v6n5p123

Jenkins, H. (2006). Small business champions for corporate social responsibility. Journal of Business Ethics, 67(3), 241-256. https://doi.org/10.1007/s10551-006-9182-6

Kakava, N. Z., Mbizi, R., \& Manyeruke, R. (2013). Beyond philanthropy to sustainable community developmentEvaluation of corporate social responsibilities activities in Zimbabwe. Interdisciplinary Journal of Contemporary Research in Business, 4(12), 674-684. https://journal-archieves31.webs.com/674-684.pdf

Miles, M. B., \& Huberman, A. M. (1994). Qualitative data analysis: An expanded sourcebook (2nd $\mathrm{ed}$.$) . Thousand Oaks,$ California: SAGE. 
Patton, M. Q. (2002). Qualitative research \& evaluation methods (3 $3^{\text {rd }}$ ed.). Thousand Oaks, California: SAGE.

Peterson, H. C. (2008). Transformational supply chains and the "wicked problem" of sustainability: Aligning knowledge, innovating, entrepreneurship, and leadership. Journal on Chain and Network Science, 9(2), 71-82. https://doi.org/10.3920/JCNS2009.x178

Researchware, Inc. (2015). HyperResearch (version 4.0.0) [Computer software]. Retrieved from http://www.researchware.com

Vermont Sustainable Jobs Fund. (2013). Farm to Plate Investment Program: 18 month report. Montpelier: Vermont Sustainable Jobs Fund, Farm to Plate Investment Program. Retrieved from http://www.vtfoodatlas.com/uploads/F2P Annual Report January 2013.pdf

Williamson, O. E. (1990). The economics of organization: The transaction cost approach. American Journal of Sociology, 87(3), 548-577. https://doi.org/10.1086/227496 